Purdue University

Purdue e-Pubs

CTRC Research Publications

Cooling Technologies Research Center

2019

Experimental Investigation of Boiling Regimes in a Capillary-Fed Two-Layer Evaporator Wick

S. Sudhakar

Purdue University

JA. Weibel

Purdue University, jaweibel@purdue.edu

S V. Garimella

Purdue University, sureshg@purdue.edu

Follow this and additional works at: https://docs.lib.purdue.edu/coolingpubs

Sudhakar, S.; Weibel, J A.; and Garimella, S V., "Experimental Investigation of Boiling Regimes in a Capillary-Fed Two-Layer Evaporator Wick" (2019). CTRC Research Publications. Paper 340.

http://dx.doi.org/https://doi.org/10.1016/j.ijheatmasstransfer.2019.03.008

This document has been made available through Purdue e-Pubs, a service of the Purdue University Libraries. Please contact epubs@purdue.edu for additional information. 


\title{
Experimental Investigation of Boiling Regimes in a Capillary-Fed Two- Layer Evaporator Wick ${ }^{1}$
}

\author{
Srivathsan Sudhakar, Justin A. Weibel ${ }^{2}$, Suresh V. Garimella \\ School of Mechanical Engineering \\ Purdue University, 585 Purdue Mall, West Lafayette, IN 47907 USA
}

\begin{abstract}
Vapor chambers with transformative evaporator wick designs capable of passively dissipating high heat fluxes over large areas, while maintaining low thermal resistances, can meet the thermal management needs of next-generation power semiconductor devices. Our prior work proposed a two-layer evaporator wick structure to enhance the performance of vapor chambers operating at high heat fluxes. The current study experimentally characterizes the capillary-fed boiling heat transfer behavior in such a two-layer evaporator wick, compared to a homogeneous (single-layer) wick, over a $1 \mathrm{~cm}^{2}$ evaporator area. The two-layer design comprises a thin base wick layer that is fed with liquid from a thick cap wick layer above using an array of vertical posts. The two-layer wick is fabricated using a sequence of sintering and laser-machining steps to form the base wick layer $(200 \mu \mathrm{m})$, array of liquid-feeding posts, and cap wick layer $(800 \mu \mathrm{m})$ using 90 $106 \mu \mathrm{m}$ copper particles. A test facility is constructed to replicate the conditions that exist at the evaporator of a vapor chamber; the novel facility design uses a physical restriction to prevent flooding of the wicks during testing. Two-layer wicks having $5 \times 5$ and $10 \times 10$ arrays of liquid feeding posts are characterized, along with a $200 \mu \mathrm{m}$-thick single-layer evaporator wick. The $10 \times 10$ array provides a $>400 \%$ enhancement in the dryout heat flux compared to the single-layer wick. High-speed visualizations are used to identify the characteristic regimes of boiling operations for the wicks. The single-layer wick exhibits a partial dryout mode of operation, where a dry spot formed in the center of the heated evaporator area causes an increase in the thermal resistance with heat flux. In contrast, the distributed feeding provided by the two-layer wicks mitigates the development of this partial dryout regime and maintains a constant low resistance $(\sim 0.1 \mathrm{~K} / \mathrm{W})$ during capillary-fed boiling until a complete dryout event occurs. This study demonstrates the significant enhancement in dryout heat flux offered by the liquid-feeding approach realized in the two-layer evaporator wicks characterized here.
\end{abstract}

\footnotetext{
${ }^{1}$ Submitted for possible publication in International Journal of Heat and Mass Transfer, 2018.

${ }^{2}$ Corresponding author, E-mail address: jaweibel@purdue.edu.
} 


\section{Keywords}

Evaporator wick, two-layer wick, dryout, capillary-fed boiling, vapor chamber, thermal resistance, high-heat-flux dissipation 


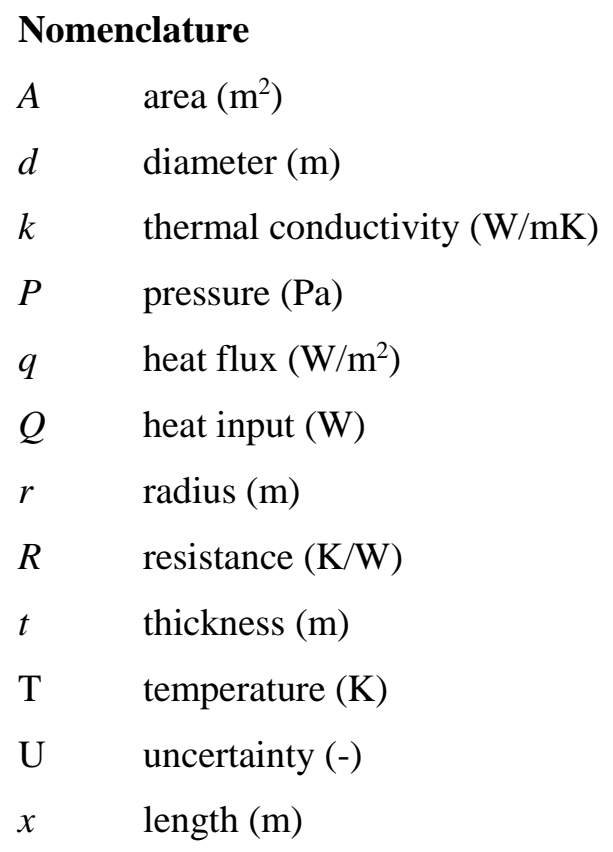




\section{Introduction}

Thermal management of high-performance radar and automotive power electronic systems requires high power densities to be dissipated while maintaining low device temperatures. The device performance in these applications is thermally limited by the amount of heat that can be rejected to the surroundings. Flat heat pipes or vapor chambers offer an effective but passive means of heat spreading from a localized heat input area (at the evaporator) to a large heat-rejection area (the condenser) where heat can be transferred to an ultimate heat sink. Vapor chambers comprise a sealed cavity lined on the inside with a porous wick that captures and pumps the working liquid via capillary action to the heat input area, where it evaporates or boils. The vapor generated in the evaporator spreads through the vapor core and is condensed back to the liquid state at the larger heat-rejection area. This two-phase operation leads to passive heat spreading at temperature differences that can be orders of magnitude lower than in the case of solid heat spreaders.

Traditional cylindrical heat pipe designs were developed for low power applications where evaporation of the working fluid from a saturated porous wick is the primary mode of heat transfer in the heat input region. The bulk wick properties including the permeability, porosity, and effective thermal conductivity determine the capillary-limited maximum heat load that can be dissipated in such applications $[1,2,3]$. As the heat fluxes increase, the menisci sustained in the interstitial pores of the wick recede into the bulk of the wick until the evaporator ultimately dries out due to a lack of adequate liquid supply (known as the capillary limit). It was conventionally understood that the onset of nucleate boiling would significantly impede liquid flow in the evaporator wick and cause dryout immediately upon incipience (known as the boiling limit) [4,5]. However, recent characterizations of sintered porous wicks have demonstrated that capillary-fed boiling can in fact be a sustained regime of operation, provided that a wick structure has many tortuous porous pathways for liquid resupply. In these cases, the surface temperature suddenly drops when boiling is initiated because the conduction resistance through the saturated wick is effectively bypassed $[6,7,8]$. In such applications where boiling is sustained in the evaporator area, the capillary feeding through the evaporator wick (over the heat input area) imposes the limiting hydraulic resistance (due to the large pressure drop) [9]. Therefore, it is critical to study the design of evaporator wicks that help sustain boiling

without impeding capillary liquid supply to the heat input area, while also maintaining low surface temperatures.

Sintered metal powder is widely used in evaporator wicks owing to the high capillary pressure and thermal conductivity of sintered wicks [5] compared to other types of wicks such as screen meshes and grooved wicks. The stochastic nature of pores in such sintered wicks can increase the interstitial area for heat transfer and provide many pathways for liquid supply, thereby sustaining high-heat-fluxes during capillary-fed boiling. While uniform-thickness, homogeneous sintered wicks are commonly considered, the 
specific choice of the wick properties is constrained by various tradeoffs. It has been shown that thin sintered wicks on the order of $\sim 200 \mu \mathrm{m}$ thick offer low resistance during boiling [10] but cannot sustain large heat loads. Conversely, thick wicks consisting of multiple particle layers provide large dryout heat fluxes [11] albeit at a high thermal resistance. Smaller particle sizes provide higher capillary pressure but lower flow permeability, whereas larger particles offer higher permeability at the cost of reduced capillary pressure. Biporous wicks having two characteristic pore sizes can simultaneously offer high capillary pressure sustained in the smaller pores and high permeability pathways through the larger pores $[12,13]$. While biporous wicks have been shown to dissipate very high heat fluxes (up to $990 \mathrm{~W} / \mathrm{cm}^{2}$ ), multiple layers of particles are usually needed to provide improvement over monoporous designs, and hence they incur very large thermal resistances (surface superheats up to $147 \mathrm{~K}$ at the maximum heat flux) [12].

A number of efforts to fabricate and characterize heterogeneous or hybrid evaporator wick designs have aimed to enhance boiling heat transfer during high heat flux operation compared to homogeneous wicks. These designs make use of dedicated feeding structures to enhance liquid supply while also providing vapor removal pathways. In pool boiling, recent studies have used porous wicks made from modulated post designs [14] or containing re-entrant cavities [15] to enhance the heat transfer coefficient and improve the critical heat flux (CHF). For enhanced capillary-fed boiling in evaporator wicks, heterogeneous wick designs aim to provide simultaneous high capillary pressure and high permeability, as an alternative to thick biporous wicks. Ryu et al. [16] used metal foam layers to supply liquid to a thin micro-post wick to achieve high dryout heat fluxes greater than $400 \mathrm{~W} / \mathrm{cm}^{2}$. The high capillary pressure of the micro-post layer helped sustain liquid menisci, while the high-permeability metal foam provided auxiliary liquid supply. In an alternative approach, screen meshes were sintered on top of rectangular microchannels to serve as an evaporator wick by Dai et al. [17]. The screen meshes contained smaller pore sizes that could enhance capillary pressure while the microchannels provided a high permeability liquid-feeding pathway from below. Weisenseel et al. [18] employed silicon carbide wicks with horizontal vapor removal channels to reduce thermal resistance at the evaporator of loop heat pipes. In addition, lateral or columnar arteries that supply a thin layer of wick [19] as well as grid-patterned wicks [20,21] have all been shown to increase the dryout heat flux while reducing the surface superheat during capillary-fed boiling, as compared to homogeneous wicks.

The current study experimentally investigates boiling behavior in a capillary-fed two-layer evaporator wick design [22]. The two-layer evaporator wick comprises a thin sintered porous base wick layer that is supplied with liquid from a thick sintered cap layer above, via an array of vertical porous posts. A novel experimental facility is developed for testing wicks in a capillary-fed situation that replicates the conditions near the evaporator region of a vapor chamber. Two designs of the two-layer wick are tested and compared to a homogeneous (single-layer) evaporator wick. The two-layer wicks provide a significant enhancement 
in the dryout heat flux while maintaining a low thermal resistance, as anticipated by the design rationale. High-speed visualizations are acquired in order to map these results to the different boiling behaviors exhibited by the single- and two-layer wicks.

\section{Two-Layer Evaporator Wick Design and Fabrication}

The two-layer evaporator wick is explained in brief here; our previous work [22] introduced the design and rationale in detail. Figure 1 shows a three-dimensional view of the design, with the liquid and vapor flow pathways indicated. The evaporator wick consists of a thick cap layer (thickness $t_{c a p}$ ) that evenly routes liquid through an array of vertical liquid-feeding posts (diameter $d_{p o s t}$ ) to a thin base layer (thickness $t_{\text {base }}$ ), as indicated by the blue arrows. The evaporator wick region is fed by a uniform bulk wick (thickness $t_{b u l k}$ ) from the periphery. The rationale for this design is that the thin base layer offers a low thermal resistance during capillary-fed boiling in this structure, while the posts and the cap layer provide well-distributed liquid feeding from above to prevent dryout. Cylindrical vents in the cap layer (diameter $d_{v e n t}$ ) provide highpermeability vapor venting. During operation, liquid recedes into the posts and the cap layer, providing an unimpeded pathway for vapor to flow out of the wick through the gaps between the posts and up through the vents, as indicated by the red arrows in Figure 1.

The two-layer wick is fabricated using a combination of sintering and laser machining steps as shown in Figure 2. The goal of the present study is to demonstrate and characterize the behavior of the novel twolayer wick during capillary-fed boiling; an extensive parametric analysis of the effects of particle size or other wick properties is not part of the scope. The choice of particle size and sintering conditions were informed by our previous work on pool boiling from sintered particulate surfaces [23]. Irregular copper particles manufactured by water atomization ( $\mathrm{ACu}$ Powder International) are sieved to obtain the desired range of 90-106 $\mu \mathrm{m}$ diameter particles (USA standard sieve numbers. 140 and 170). A copper substrate is sanded using 220 grit sandpaper and then inverted onto a graphite mold with a recess of the desired depth containing loose copper particles. The mold and substrate are placed inside a bell-jar vacuum furnace. The furnace is evacuated using a vacuum pump to $\sim 1.33 \mathrm{~Pa}$ over a period of $2 \mathrm{hr}$, after which a diffusion pump runs for $\sim 12 \mathrm{hr}$ to reach a high vacuum of $0.00133 \mathrm{~Pa}$. To sinter the particles, the furnace temperature is ramped over $2.5 \mathrm{hr}$ from room temperature to $950{ }^{\circ} \mathrm{C}$, and then held constant for a period of $0.5 \mathrm{hr}$. The furnace is allowed to cool down to room temperature overnight; high vacuum is held throughout cooling to avoid oxidation of the wick. Figure 2 (f) shows a scanning electron microscopy (SEM) image of the sintered wick; the irregular particles and highly tortuous nature of the pores are apparent.

A homogeneous sintered layer is fabricated in the first sintering step (Figure 2(b)). Next, a laser-cutting machine in the Birck Nanotechnology Center at Purdue University (Universal Laser Systems PLS6MW) is used to etch the sintered surface over the central area to fabricate posts and retain only a thin base wick 
layer in the region without posts (Figure 2 (c)). This non-contact machining avoids fragmentation of the sintered porous wick while fabricating the posts. Compared to using molding processes [19] to form these post-array wick structures, for which removal of the sintered sample is difficult and requires special design considerations (e.g., see Ref. [14]), laser etching allows for fabrication of comparatively smaller and denser microscale post arrays. To test the effect of the laser machining process on the wetting nature of the wick, a micro-syringe was used to deposit a $3 \mu$ deionized water droplet onto multiple locations of the native sintered wick and the laser-etched regions. High-magnification videos were recorded using a Nikor D5200 DSLR camera fitted with a Keyence VH-Z50L high-magnification zoom lens. It was observed that the laser-treated regions absorbed the liquid at a similar rate as the native regions of the wick, indicating that the laser machining process did not affect the wetting characteristics. The videos of liquid wetting a native sintered wick and a laser etched portion of the wick are included in Appendix A.

The wick configuration shown in Figure 2(c) is then inverted onto a graphite mold containing loose copper particles to sinter the second cap layer shown in Figure 2(d). Once the cap layer is sintered, the vents are fabricated by laser etching through the cap layer in the gaps between the posts (Figure 2(e)). Special care was taken, by controlling the number of laser passes, to prevent over-etching through to the exposed base wick layer. A photograph of the as-fabricated two-layer wick is shown in Figure 2(g) for a design having a $5 \times 5$ array of liquid-feeding posts and a $4 \times 4$ array of vapor vents; the complete dimensions of the fabricated wick samples are detailed in Section 4.

\section{Experimental Methods}

\subsection{Capillary-fed boiling experimental facility}

A capillary-fed boiling test facility is constructed to characterize the two-layer wick design. In order to mimic the conditions in the evaporator region of a vapor chamber, the wick must be uniformly fed with liquid from the periphery, purely via capillary action (i.e., the wick in the evaporator region should not be submerged or flooded with liquid). In addition, the wick should be placed in a saturated vapor environment. Several studies $[7,24,34]$ have tested evaporator wicks by orienting them vertically and submerging the lower edge into a liquid bath, thus avoiding any flooding over the evaporator area located above the surface of the bath. This method can provide uniform liquid feeding to small evaporator areas (a few $\mathrm{mm}^{2}$ in size) if they are located far above the liquid bath; however, the height of the evaporator region above the liquid level should be kept small to avoid incurring a large gravitational pressure drop that governs the behavior. In general, these studies note that the height of the evaporator above the liquid level can influence the phase change process and dryout heat flux. Alternatively, several studies [11,13] have characterized horizontally oriented evaporator wicks placed flush with the surface of a liquid bath; in this configuration it is difficult to maintain the liquid level to be even with the height of the thin wicks. For example, Li and Peterson [11] 
tested sintered screen mesh wicks that were placed horizontally at the surface of a saturated liquid bath and reported that flooding could have occurred in their thinnest wicks. To overcome the difficulty in maintaining the liquid level while taking advantage of horizontal liquid feeding, evaporator wicks have also been tested by placing them on raised pedestals, using a collar wick on the sidewalls of the pedestal for feeding from the bath below [12,25]. While this approach does not require precise control of the liquid level, it requires a more complicated sample fixture and must account for potential evaporation/boiling from the exposed pedestal sidewalls.

In our study, the relatively large desired heat input area $\left(1 \mathrm{~cm}^{2}\right)$ necessitates the use of horizontal liquid feeding to provide a uniform liquid supply to the evaporator wick. We develop a novel capillary-fed boiling test facility, which uses a physical restriction (i.e., a dam) to prevent flooding over the top of the horizontal wick. This approach allows the surrounding liquid level to be maintained slightly higher than the wick, to ensure continuous feeding from the sides while avoiding any risk of flooding. The need for active liquidlevel control to match the height of the wick is thereby eliminated. Note that the dam design inherently allows for some gravitational assistance to liquid-feeding because the liquid level is higher than the wick level. However, this assistance due to gravitational pressure head is negligible compared to the capillary pressure generated by the wick when operating in a capillary-fed mode (see Section 3.3).

The test facility, shown schematically in Figure 3(a), primarily consists of a test chamber, a heater block and insulation assembly, and a condenser loop. The PEEK and polycarbonate chamber side walls are sealed together using a silicone adhesive (RTV 118, McMaster Carr) and stainless steel screws, while the top wall is sealed with a compressed high-temperature rubber gasket. Deionized (DI) water is used as the working fluid; there are two T-type thermocouples each in the liquid pool and the vapor space above, and two immersion cartridge heaters $(120 \mathrm{~V}, 300 \mathrm{~W}$ each) submerged in the liquid pool. The condenser loop consists of a temperature-controlled chiller (not shown in Figure 3(a)) that is connected to a Graham condenser, attached to the top chamber wall, for degassing the liquid. The coolant (water) also routes through a copper condenser coil within the chamber to condense the vapor back to liquid to control the chamber pressure during boiling. Figure 3(b) shows a close-up view of the test facility schematic diagram near the evaporator wick and Figure 3(c) shows an exploded view of the heater assembly. A high-temperature rubber gasket is sealed against the top of the wick and held in place using a PEEK dam that prevents flooding over the wick during test. The dam has openings (seen in Figure 3(c)) to feed the wick from the sides. Thus, the dam allows the surrounding liquid to be at a higher level than the wick and allows for a large tolerance in the height at which this level should be maintained while avoiding flooding. The dam and the gasket both have openings in the middle to allow evaporation from the wick into the vapor space above through a $1 \mathrm{~cm}^{2}$ square area. 
The heater block assembly consists of a copper heater block, a ceramic insulation plate, mineral wool filler insulation, a PEEK outer casing, and a PEEK fixture that is fabricated in two pieces. The copper heater block has a stepped design that has a larger base cross section area $(45 \mathrm{~mm} \times 45 \mathrm{~mm})$ that houses nine cartridge heaters $(150 \mathrm{~W}$ each). Along the top $15 \mathrm{~mm}$, the heater block cross-section is smaller at $10 \mathrm{~mm} \times$ $10 \mathrm{~mm}$. This neck concentrates the heat input to a smaller area and interfaces directly with the wick substrate, which is soldered onto the top of the heater block (details in Section 3.2). Thermocouples are inserted into three locations along the length of the neck and in two additional lateral locations (data reduction details in Section 3.4). The thermocouples along the neck length are used to measure the heat flux and substrate temperature by extrapolation of the temperature gradient, while the lateral thermocouples are used to check if the temperature is uniform over the neck cross-section. The heater block was designed to provide a uniform one-dimensional heat input to the wick. The length of the neck is chosen to be long enough to allow for enough thermocouples to be placed to predict the heat input with good accuracy (uncertainty analysis in Section 3.4), but not so long that the gradient would incur very high temperatures at the heater base at the maximum heat flux. Conduction heat transfer simulations were performed using ANSYS Fluent [26] to confirm that the heat flow upon area reduction again became uniform across the neck cross-section at the position of the bottom-most thermocouple. The base of the heater block, which can reach temperatures exceeding the safe operating temperature of PEEK $\left(250{ }^{\circ} \mathrm{C}\right)$, is placed on a ceramic base for insulation, which is supported by springs to accommodate thermal expansion. Immediately surrounding the sides of the copper block is a layer of mineral wool that can withstand temperatures up to $1100{ }^{\circ} \mathrm{C}$.

The test chamber has a window in the top wall for visualization (Figure 3 (a)) normal to the $1 \mathrm{~cm}^{2}$ evaporating area of the wicks. To avoid condensation on the glass windows during visualization, two patch heaters are attached to the window using high-temperature Kapton tape. The high-speed videos are taken using a Phantom VEO 710L high-speed camera, fitted with Nikon Micro-Nikkor $200 \mathrm{~mm}$ lens, at a resolution of $640 \times 600$ pixels and a frame rate of $2000 \mathrm{fps}$. The visualization is aided by front lighting, using a Titan 300 fiber-optic light source, placed over the window.

\subsection{Soldering and sealing}

To achieve a low-thermal-resistance connection between the heater block and the wick substrate, they are soldered together. The heater block is fixed upright and solder flux is applied to the top surface. The block is heated to $\sim 250^{\circ} \mathrm{C}$ using the cartridge heaters and a known quantity of lead-tin solder ( $\mathrm{Pb} 30-\mathrm{Sn} 70$; melting point of $249^{\circ} \mathrm{C}$; thermal conductivity, $k_{s}$ of $41 \mathrm{~W} / \mathrm{mK}$ ) is then deposited on the surface. The solder melts while the flux allows it to wet the copper and spread uniformly over the $1 \mathrm{~cm}^{2}$ surface. The heater block is then cooled down to room temperature and placed inverted onto the wick substrate, using a graphite 
fixture to center the heater block with respect to the substrate (as shown in the assembly in Figure 4 (a)). The heater block is again heated to $250{ }^{\circ} \mathrm{C}$ to melt the solder and form a joint between the heater block and substrate.

To characterize the thickness and uniformity of the soldered joint, a non-destructive $\mu$-CT scan (Bruker Skyscan 1272) of the soldered joint was performed in the Center for Particulate and Powder Processing at Purdue University, with a $2452 \times 1640$ pixel detector resolution and a reconstructed voxel size of $3.5 \mu \mathrm{m}$. The soldered joint thickness is measured to be $t_{s}=150 \mu \mathrm{m}$ from the $\mu$-CT scan images. A cross section through the center of the joint reveals some voids scattered throughout; a void fraction of $15 \%$ was calculated from the scan images. Due to the high conductivity and small thickness of the solder joint, the effect of this porosity on the extrapolated substrate temperature is less than the uncertainty in its calculation (see Section 3.4). To obtain a conservative (highest) estimate of the substrate temperature, the uncertainty caused by the porosity of the solder joint is omitted. After each test, the substrate/wick is detached from the heater block by reheating it to the melting point of the solder. The top surface of the heater block is then sanded using 320 grit sandpaper to remove any residual solder before the next sample is attached.

Sintered copper wicks, although intrinsically hydrophilic, can become nonwetting on prolonged exposure to air [27]. It is critical to ensure the hydrophilicity of a copper wick, as any degradation in the wettability can drastically affect the maximum heat flux that can be dissipated when a wick operates under capillary action [28]. Previous studies that tested copper wicks typically used chemical [29] or thermal [30] functionalization techniques to grow a stable wetting copper oxide or reduce the wicks to pure copper [2,7] prior to testing. In this study, prior to sealing the heater block and wick into the test facility, the wick is dipped in a solution of $2 \mathrm{M} \mathrm{NaOH}$ and $0.1 \mathrm{M}\left(\mathrm{NH}_{4}\right)_{2} \mathrm{~S}_{2} \mathrm{O}_{8}$ for $30 \mathrm{~min}$ to form $\mathrm{Cu}$ (II) oxide, following the procedure of Chen et al. [31], which maintains the wettability of the wick throughout the duration of a test.

There are multiple seals in the heater block and insulation assembly (see Figure 3 (c)) to avoid leaks in the test chamber. The heater assembly is interfaced with the test chamber using a PEEK fixture that is fabricated in two pieces. After the solder joint is formed, the mineral wool insulation is stuffed between the heater block and the surrounding PEEK assembly. The two pieces of the fixture are then sealed together with silicone adhesive (RTV 118, McMaster Carr). The heater block assembly is then sealed against the bottom wall of the test chamber using an o-ring placed in a groove on the fixture. The rubber gasket on the underside of the wick substrate provides a seal to the fixture below; the rubber gasket on top of the wick seals against the dam to prevent flooding. The dam is pressed on top of the wick using four screws that compress these gaskets. 


\subsection{Testing procedure}

After sealing, deionized water is manually added to the chamber to a level above the wick height, but lower than the dam height (as shown in Figure 3 (b)). The total volume of liquid inside the chamber reduces slightly during degassing and otherwise remains constant through the duration of the test. Before running the test, the top of the chamber is sealed and the heat input to the immersion heaters is turned on to vigorously boil and degas the liquid inside the chamber while keeping the valve to the Graham condenser open to atmosphere. The Graham condenser allows pure vapor to condense back to the chamber while purging non-condensable gases. Towards the end of the degassing process, small air bubbles no longer appear in the chamber, and only larger vapor bubbles that nucleate off the immersion heaters remain. After degassing, the valve to the Graham condenser is closed, sealing the test chamber from the surrounding ambient. The metering valve is opened to adjust the flow rate of the coolant into the condenser coil within the chamber; this controls the pressure within the chamber. The pressure inside the chamber is actively adjusted to be slightly above ambient throughout the duration of the test. In this manner, a saturated environment is maintained within the chamber.

In order to acquire a boiling curve, the power input to the cartridge heaters within the heater block is increased in steps. At each input power level, the system is allowed to reach a steady state, which is defined to have been achieved when the rate of change of the temperatures in the heater block are within $0.1 \mathrm{C} / \mathrm{min}$, measured over a period of $10 \mathrm{~min}$. The temperatures and pressures are recorded at steady state. The power input level is increased till a dryout heat flux is reached. Dryout is characterized by a sudden overshoot in surface temperature, which happens when the wick is no longer capable of feeding liquid to the heat input area.

When water is initially filled to a level above the wick and no evaporation is occurring, the wick becomes flooded as the small gravitational pressure head drives the fluid through the pores of the wick. After the heat input to the heater block is turned on, a certain minimum value of heat flux is required for the rate of evaporation from the wick to match the rate of gravitational liquid feeding from the surrounding reservoir. Above this heat flux, the liquid completely recedes into the evaporator wick, forming menisci on the wick surface that drive operation in a capillary-fed regime. The influence of gravitational liquid feeding on the maximum dryout heat flux can be confirmed to be negligible based on a simple comparison of the gravitational pressure head to the capillary pressure $\left(P_{c}=2 \sigma / r_{p}\right.$, where $r_{p}$ is the pore radius calculated based on the average particle diameter). This calculation confirms that the capillary pressure is $\sim 60$ times higher than the gravitational pressure head, based on the liquid level being maintained at $\sim 1 \mathrm{~cm}$ above the wick for the duration of the test. 


\subsection{Data reduction and uncertainty characterization}

The heater block (Figure 4 (b)) has three thermocouples along the neck to measure the heat flux using a linear fit

$$
q^{\prime \prime}=-\left.k_{C u} \frac{\partial T}{\partial x}\right|_{\text {linear }}
$$

The substrate temperature is then calculated using an extrapolation of the thermocouple reading closest to the substrate $\left(T_{1}\right)$ as,

$$
T_{\text {sub }}=T_{1}-q^{\prime \prime}\left(\frac{x_{1}}{k_{C u}}+\frac{t_{s}}{k_{s}}\right)
$$

where $x_{l}$ is the distance from the solder joint to thermocouple location $T_{l}$,

The thermal resistance of the wick is characterized based on the difference in temperatures of the substrate and the vapor space,

$$
R_{\text {wick }}=\frac{T_{s u b}-T_{v a p}}{q^{\prime \prime} A_{h}}
$$

where the temperature of the vapor space is taken as the average of the two thermocouple readings, which is confirmed to be equal to the saturation temperature calculated based on the measured vapor pressure inside the chamber.

A comprehensive uncertainty analysis is carried out to calculate the uncertainty propagation from the sensor measurements to the heat flux, substrate temperature, and resistance calculations, following Brown et al. [32]:

$$
U_{R_{\text {wick }}}=\left(\frac{U_{T_{\text {sub }}}{ }^{2}}{\left(T_{\text {sub }}-T_{\text {vap }}\right)^{2}}+\frac{U_{T}{ }^{2}}{\left(T_{\text {sub }}-T_{\text {vap }}\right)^{2}}+\frac{U_{q^{\prime \prime}}{ }^{2}}{q^{2}}\right)^{1 / 2} R_{\text {wick }}
$$

where,

$$
\begin{gathered}
U_{q^{\prime \prime}}=\left[\sum_{i=1}^{3}\left(\frac{\partial q^{\prime \prime}}{\partial T_{i}}\right)^{2} U_{T}{ }^{2}+\sum_{i=1}^{3}\left(\frac{\partial q^{\prime \prime}}{\partial x_{i}}\right)^{2} U_{x}{ }^{2}\right]^{1 / 2} \\
U_{T_{s u b}}=\left[U_{T}{ }^{2}+\left(\frac{x_{1}}{k_{C u}}+\frac{t_{s}}{k_{s}}\right)^{2} U_{q^{\prime \prime}}{ }^{2}+\left(\frac{q^{\prime \prime}}{k_{C u}}\right)^{2} U_{x}{ }^{2}\right]^{1 / 2}
\end{gathered}
$$

Equations (5) and (6) respectively show the uncertainties in the heat flux (slope of the linear fit) and substrate temperature (extrapolated from intercept); the complete expressions for the derivatives in equation (5) can be found in Ref. [32]. The thermocouples are calibrated using a Jupiter 4852 dry block calibrator 
for a wide range of temperatures from $50-200{ }^{\circ} \mathrm{C}$. For each set value in the calibrator, the thermocouples are allowed to reach steady state and the voltage readings are recorded. The voltage readings are converted to temperature values using the ITS-90 standard polynomial curve for T-type thermocouples. Based on the difference between the set values and the measured thermocouple values, the uncertainty in the thermocouple measurements, $U_{T}$, is taken as $\pm 0.3 \mathrm{~K}$. The uncertainty in the position of the thermocouple, $U_{x}$, is taken as $\pm 0.2 \mathrm{~mm}$, based on the clearance between the thermocouple probes and machined insertion holes.

\section{Results}

Thermal test results for three different cases are reported: a baseline wick with a homogeneous, single layer of sintered particles over the evaporator area, and two-layer evaporator wicks with two different liquid-feeding post array designs. Figure 5 shows a plan view of these wicks. All the wicks are sintered on $38.1 \mathrm{~mm} \times 38.1 \mathrm{~mm}$ square copper substrates and cover the central $30 \mathrm{~mm} \times 30 \mathrm{~mm}$ area. The evaporator wick covers the central $10 \mathrm{~mm} \times 10 \mathrm{~mm}$ heated area, while the $1500 \mu \mathrm{m}$ thick surrounding feeding wick is the same across all the designs. The baseline homogeneous wick shown in Figure 5 (a) has a thin layer of sintered particles in the evaporator area, with a thickness equal to the base wick thickness $(200 \mu \mathrm{m})$ in the two-layer designs. This wick is fabricated by first using sintering to make the $1500 \mu \mathrm{m}$ thick wick (as described in Section 2, Figure 2(b)), followed by laser machining the middle $1 \mathrm{~cm}^{2}$ area to leave the 200 $\mu \mathrm{m}$ thick layer behind. The choice of dimensions across the three wicks tested allows direct evaluation of the efficacy of the additional liquid-feeding and vapor venting features included in the two-layer designs. Two designs of the two-layer wick (shown in Figure 5 (b) and (c)) are tested: a $5 \times 5$ post array design $\left(d_{\text {post }}=1 \mathrm{~mm}, d_{\text {vent }}=1 \mathrm{~mm}\right)$ and a $10 \times 10$ post array design $\left(d_{\text {post }}=0.5 \mathrm{~mm}, d_{\text {vent }}=0.5 \mathrm{~mm}\right)$. The posts are uniformly arranged in a square array over the $1 \mathrm{~cm}^{2}$ evaporator area and the vents are offset from the posts. Other dimensions of the two-layer wicks that are kept the same in these two designs are: $t_{\text {base }}=200 \mu \mathrm{m}, t_{c a p}$ $=800 \mu \mathrm{m}, t_{\text {bulk }}=1500 \mu \mathrm{m}$, and $t_{\text {post }}=500 \mu \mathrm{m}$. The choice of two-layer wick designs is informed by the reduced-order thermal-fluid transport model we had previously developed [22] to estimate the key pressure drops and thermal resistances in a vapor chamber incorporating a two-layer wick at the evaporator. The total pressure drop of the vapor chamber is compared against the capillary pressure of the wick to estimate the capillary-limited maximum rate of heat input to the vapor chamber. A thorough parametric analysis of the two-layer wick was performed to identify the parameters that were sensitive to the performance of the vapor chamber. This model revealed that the maximum pressure drop is incurred by fluid flow through the thin base layer and the formulation of this base layer can significantly affect the dryout heat flux. Moreover, increasing the liquid-feeding post array size from $5 \times 5$ to $10 \times 10$ was shown to support an increase in the dryout heat flux, because denser post arrays reduce the size of the evaporator area that each post must feed. 


\subsection{Baseline single-layer evaporator wick}

The homogeneous evaporator wick (Figure 5 (a)), with no liquid feeding or vapor venting features, is first tested to serve as a benchmark against which to compare the two-layer wicks. As reviewed in Section 1, thin single-layer evaporator wicks can provide a low thermal resistance, but cannot sustain capillary-fed boiling over large heat input areas at high heat fluxes due to restricted liquid feeding from the periphery.

The black curves in Figure 6 (a) and (b) respectively show the boiling curve (measured heat flux versus substrate superheat) and the thermal resistance data for the homogeneous wick. With increasing heat flux, the substrate temperature increases monotonically. Nucleate boiling was visually observed within the capillary-fed wick at the first steady heat flux of $\sim 24 \mathrm{~W} / \mathrm{cm}^{2}$ (at a substrate superheat of $3.1 \mathrm{~K}$ ), and for all subsequent steady-state data during the test. At low heat fluxes $\left(<45 \mathrm{~W} / \mathrm{cm}^{2}\right)$, the slope in the boiling curve is linear and the thermal resistance remains almost constant at $\sim 0.118 \mathrm{~K} / \mathrm{W}$. After this initial linear rise in superheat with heat flux, a distinct reduction in the slope of the boiling curve is observed at heat fluxes great than $>45 \mathrm{~W} / \mathrm{cm}^{2}$, which corresponds to an increase in the wick resistance, as seen in Figure 6 (b).

Visualizations from high-speed videos (see Appendix B) are used to identify and explain the mechanism that causes this increase in thermal resistance when the homogeneous wick is in the capillaryfed boiling regime. Figure 7 shows top-down images of the wick extracted from the high-speed videos at different steady values of heat fluxes for the homogeneous wick, along with representative cross-sectional schematic diagrams explaining the associated boiling regimes observed in the evaporator wicks. At 45 $\mathrm{W} / \mathrm{cm}^{2}$ and below, the entire $1 \mathrm{~cm}^{2}$ heated area of the wick undergoes boiling while being fed by the surrounding bulk wick. This is seen in the image taken at $45 \mathrm{~W} / \mathrm{cm}^{2}$ in Figure 7 (a); the apparent shiny surface of the wick here indicates that liquid menisci are sustained near the top of the saturated wick surface during capillary feeding. This mode of operation, described by the corresponding diagram in Figure 7 (a) and characterized by boiling occurring over the entire heated area, maintains a constant and low value of thermal resistance. As the heat flux increases, a dry spot forms in the middle of the heated area, as shown in the image at $65 \mathrm{~W} / \mathrm{cm}^{2}$ (Figure 7 (b)). The wick is not able to sustain this heat flux over the large heat input area and hence starts to dry out in the region farthest from the edge of the wick. This partial dryout phenomenon causes a rise in thermal resistance. With further increases in heat flux, the dry spot grows to nearly the size of the entire heated area. The image taken at the last steady data point, $98 \mathrm{~W} / \mathrm{cm}^{2}$ (Figure 7 (c)), shows that the heated area is almost completely dry, with boiling observed only at the edges. A small increase in heat input above this last steady heat flux causes the surface temperature to rise dramatically due to complete dryout of the wick. The test is stopped after the wick appears completely dry in the visualization. 
This phenomenon of local or partial dryout has been previously observed during capillary-fed boiling in single-layer porous wicks over relatively large heat input areas. Nam et al. [33] reported partial dryout in micro-post wicks and observed that nano-structuring the posts helped to delay the onset of partial dryout owing to enhanced capillary performance. Cai and Chen [34] observed local dryout in carbon nanotube biporous wick structures for larger input areas $\left(1 \mathrm{~cm}^{2}\right)$ but did not observe it for smaller hotspots $\left(0.04 \mathrm{~cm}^{2}\right)$. When boiling occurs in a capillary-fed wick, the area furthest from the edge of the heated area (from where it is drawing liquid) dries out first. This is due to the larger pressure drop that is incurred to feed liquid over the longer distance to the center of the heated area.

\subsection{Two-layer evaporator wick}

Figure 6 shows the boiling curves and the wick thermal resistance for the $5 \times 5$ and $10 \times 10$ post array designs. Unlike the single-layer wick that dries out partially at low heat fluxes, causing an unfavorable increase in thermal resistance, both these two-layer wick designs exhibit a low resistance for the entirety of the boiling curve. It can be seen that there is a small reduction in the thermal resistance with increasing heat flux up to $\sim 100 \mathrm{~W} / \mathrm{cm}^{2}$, after which it remains nearly constant (at a low value of $0.1 \mathrm{~K} / \mathrm{W}$ ) for both twolayer wicks. The thermal resistance curves confirm that partial dryout does not occur in the two-layer wick. This favorable suppression of partial dryout over the heated area is due to liquid feeding from the cap layer through the vertical posts that uniformly distribute liquid to the thin base layer below. In addition, the thermal resistance $(\sim 0.1 \mathrm{~K} / \mathrm{W})$ of the two-layer wicks is similar to that value for the thin single-layer wick prior to partial dryout when the entire heater area was boiling (as shown and represented in Figure 7 (a)). Hence, it can be inferred that there is no adverse effect due to the additional feeding features in the twolayer wick, including the posts and cap layer, because they are designed to minimizing the impedance to vapor outflow while providing top-down liquid supply. A small increase in the heat flux above the highest steady-state result shown for the two-layer wicks in Figure 6 results in a sudden overshoot in the substrate temperature. For the $5 \times 5$ wick, dryout caused the substrate temperature to increase from $\sim 115{ }^{\circ} \mathrm{C}$ to $\sim 135$ ${ }^{\circ} \mathrm{C}$ without reaching a steady state. The test was stopped due to this observation of a sudden temperature overshoot. The dryout heat flux of the two-layer wicks is compared against the homogeneous wick at the onset of partial dryout: the $5 \times 5$ design has a dryout heat flux of $151 \mathrm{~W} / \mathrm{cm}^{2}$ at $0.095 \mathrm{~K} / \mathrm{W}$, which is $\sim 3.4$ times larger than the onset of partial dryout in the single-layer wick $\left(45 \mathrm{~W} / \mathrm{cm}^{2}\right.$ at $\left.0.113 \mathrm{~K} / \mathrm{W}\right)$; the $10 \times 10$ design has an even higher dryout heat flux of $198 \mathrm{~W} / \mathrm{cm}^{2}$ at $0.105 \mathrm{~K} / \mathrm{W}$, a $\sim 4.4$ times enhancement over the baseline.

High-speed visualizations (see Appendix B) and the corresponding images shown in Figure 8 reveal the capillary-fed boiling behavior and confirm that the liquid and vapor phase are separated during highheat-flux operation with this two-layer design, thus providing an unimpeded pathway for vapor to escape 
through the vents without disrupting the liquid feeding. The two-layer evaporator wick designs exhibit notably different boiling mechanisms compared to the homogeneous wick. At low heat fluxes, active bubbling can be seen to occur up through the vents of the wick, as shown in the image at $98 \mathrm{~W} / \mathrm{cm}^{2}$ in Figure 8 (a). The surrounding cap layer appears shiny, indicating that it is saturated with liquid. It can be inferred that the spaces between the posts within the two-layer wick remain filled with liquid during this initial stage, causing bubbling through the vents as drawn in the schematic diagram in Figure 8 (a). The measured resistance in this regime, where saturated liquid is present within the spaces of the wick, is $0.115 \mathrm{~K} / \mathrm{W}$. As the heat flux is increased, a fraction of the vents stop bubbling, as seen in the image at 152 $\mathrm{W} / \mathrm{cm}^{2}$ (Figure 8 (b)). This indicates that the liquid inside the open spaces of the two-layer wick has started to recede into the surrounding wick, thus leading to a regime where jets of vapor are ejected out of the vents, as drawn in the corresponding schematic diagram. This causes a slight decrease in thermal resistance in this regime, due to the reduced impedance to vapor flow. With further increases in heat flux, bubbling is not seen in the vents (see the image at $198 \mathrm{~W} / \mathrm{cm}^{2}$ in Figure 8 (c)), indicating that vapor fills the spaces within the wick. In this separated flow regime, the vapor has an unimpeded flow pathway through the gaps between the posts and out through the vents; the wick resistance is a minimum. It is important to note that the base layer of the wick is still boiling in this regime, as inferred from the low value of wick resistance and observation of bubbling in the base layer seen though the vents. There is no occurrence of a local or partial dryout in the two-layer wick, which would otherwise have caused an increase in thermal resistance, and the posts are able to continually feed the entire base layer during high-heat-flux boiling operation. After the last steady data point at $198 \mathrm{~W} / \mathrm{cm}^{2}$, there is a sudden rise in substrate temperature due to a complete dryout of the base wick layer.

The two-layer wick investigated here has a different behavior compared to other hybrid wicks with enhanced lateral liquid-feeding features that have been previously reported in the literature. Hwang et al. [24] evaluated wicks having lateral converging arteries that supply a thin base wick layer They reported an increase in thermal resistance with increasing heat fluxes, signifying partial dryout of the thin layer. In this design, the lateral direction of feeding to the center of the evaporator area allows for starvation of the base wick at high-heat-fluxes, causing partial dryout. In contrast, the current two-layer wick design has a topdown feeding approach where the posts are evenly distributed over the base layer, providing uniform liquid supply to the entire base layer from the thick cap layer. This top-down feeding approach avoids local/partial dryout and the associated thermal resistance penalty.

\section{Conclusions}

Capillary-fed boiling heat transfer in a novel, two-layer evaporator wick structure proposed by the authors is experimentally studied. A novel capillary-fed boiling experimental setup is developed that 
simulates the conditions near the evaporator region within a vapor chamber. Three designs of evaporator wicks are tested: a single-layer wick and two designs of the two-layer evaporator wick. The experiments are aided by high-speed visualization to image the evaporator area. The major findings from this study are listed below:

1. The single-layer wick exhibits partial dryout; i.e., dryout in the center of the wick causes an increase in the measured thermal resistance. The dry region expands as the heat flux increases, and ultimately leads to a complete dryout event. The two-layer wicks avoid the occurrence of partial dryout owing to distributed flow to the entire heated region; a single complete dryout event is observed at much higher heat fluxes.

2. The two-layer wicks extend the dryout heat flux of the single-layer wick while maintaining the same value of boiling thermal resistance as the single-layer wick. This indicates that the feeding structures (viz., the posts and cap layer) impose no additional resistance over the boiling resistance of the thin base layer.

3. Denser arrays of liquid feeding posts in the two-layer wick provide an improvement in the dryout heat flux, due to more distributed liquid feeding to the base layer. The $5 \times 5$ two-layer wick dried out completely beyond $151 \mathrm{~W} / \mathrm{cm}^{2}$ while dryout was extended in the $10 \times 10$ two-layer wick up to $198 \mathrm{~W} / \mathrm{cm}^{2}$.

4. High-speed visualization images helped identify different boiling regimes during the capillary-fed operation of the single- and two-layer wicks. While partial dryout was observed for the single-layer wick, the two-layer wick operates in a separated-flow regime during high-heat-flux operation. In this mode, the liquid-feeding and vapor removal mechanisms are separated, offering unimpeded flow pathways for liquid and vapor.

\section{Acknowledgements}

This material is based upon work supported by Toyota Motor Engineering and Manufacturing North America, Inc. under an Advanced Research Collaboration with Dr. Feng Zhou and Dr. Ercan M. Dede at the Toyota Research Institute of North America.

\section{Appendix A}

The supplementary high-magnification videos of liquid wetting behaviors can be found online.

\section{Appendix B}

The supplementary high-speed videos associated with Figure 7 and 8 can be found online. 


\section{References}

[1] Y. X. Wang and G. P. Peterson, "Analytical Model for Capillary Evaporation Limitation in Thin Porous Layers," Journal of Thermophysics and Heat Transfer, vol. 17, pp. 145-149, 2003.

[2] B. D. Iverson, T. W. Davis, S. V. Garimella, M. T. North, and S. S. Kang, "Heat and Mass Transport in Heat Pipe Wick Structures," Journal of Thermophysics and Heat Transfer, vol. 21, pp. 392-404, 2007.

[3] K. S. Udell, "Heat transfer in porous media heated from above with evaporation, condensation, and capillary effects," Journal of Heat Transfer, vol. 105, pp. 485-492, 1983.

[4] A. Brautsch and P. A. Kew, "Examination and visualisation of heat transfer processes during evaporation in capillary porous structures," Applied Thermal Engineering, vol. 22, pp. 815-824, 2002.

[5] A. Faghri, "Heat Pipe Science and Technology," Taylor \& Francis, Washington, DC, 1995.

[6] R. R. Williams and D. K. Harris, "A device and technique to measure the heat transfer limit of a planar heat pipe wick," Experimental Thermal and Fluid Science, vol. 30, pp. 277-284, 2006.

[7] J. A. Weibel, S. V. Garimella, and M. T. North, "Characterization of evaporation and boiling from sintered powder wicks fed by capillary action," International Journal of Heat and Mass Transfer, vol. 53, pp. 4204-4215, 2010.

[8] C. Li and G. P. Peterson, "Evaporation/Boiling in Thin Capillary Wicks (II)-Effects of Volumetric Porosity and Mesh Size," J. Heat Transfer, vol. 128, pp. 1320-1328, 2006.

[9] J. A. Weibel and S. V. Garimella, "Chapter Four - Recent Advances in Vapor Chamber Transport Characterization for High-Heat-Flux Applications," Advances in Heat Transfer, vol. 45, Elsevier, pp. 209-301, 2013.

[10] A. S. Kousalya, J. A. Weibel, S. V. Garimella, and T. S. Fisher, "Metal functionalization of carbon nanotubes for enhanced sintered powder wicks," International Journal of Heat and Mass Transfer, vol. 59, pp. 372-383, 2013.

[11] C. Li, G. P. Peterson, and Y. Wang, "Evaporation/Boiling in Thin Capillary Wicks (1)—Wick Thickness Effects," J. Heat Transfer, vol. 128, pp. 1312-1319, 2006.

[12] T. Semenic and I. Catton, "Experimental study of biporous wicks for high heat flux applications," International Journal of Heat and Mass Transfer, vol. 52, pp. 5113-5121, 2009.

[13] C. Byon and S. J. Kim, "Effects of geometrical parameters on the boiling limit of bi-porous wicks," International Journal of Heat and Mass Transfer, vol. 55, pp. 7884-7891, 2012.

[14] Y. Nasersharifi, M. Kaviany, and G. Hwang, "Pool-boiling enhancement using multilevel modulated wick," Applied Thermal Engineering, vol. 137, pp. 268-276, 2018. 
[15] D. Deng, W. Wan, J. Feng, Q. Huang, Y. Qin, and Y. Xie, "Comparative experimental study on pool boiling performance of porous coating and solid structures with reentrant channels," Applied Thermal Engineering, vol. 107, pp. 420-430, 2016.

[16] S. Ryu, J. Han, J. Kim, C. Lee, and Y. Nam, "Enhanced heat transfer using metal foam liquid supply layers for micro heat spreaders," International Journal of Heat and Mass Transfer, vol. 108, Part B, pp. 2338-2345, 2017.

[17] X. Dai, F. Yang, R. Yang, Y.-C. Lee, and C. Li, "Micromembrane-enhanced capillary evaporation," International Journal of Heat and Mass Transfer, vol. 64, pp. 1101-1108, 2013.

[18] B. Weisenseel, P. Greil, and T. Fey, "Biomorphous Silicon Carbide as Novel Loop Heat Pipe Wicks," Advanced Engineering Materials, vol. 19, p. 1600379, 2016.

[19] Y. S. Ju, M. Kaviany, Y. Nam, S. Sharratt, G. S. Hwang, I. Catton, E. Fleming and P. Dussinger, "Planar vapor chamber with hybrid evaporator wicks for the thermal management of high-heat-flux and high-power optoelectronic devices," International Journal of Heat and Mass Transfer, vol. 60, pp. 163-169, 2013.

[20] J. A. Weibel, S. S. Kim, T. S. Fisher, and S. V. Garimella, "Carbon Nanotube Coatings for Enhanced Capillary-Fed Boiling from Porous Microstructures," Nanoscale and Microscale Thermophysical Engineering, vol. 16, pp. 1-17, 2012.

[21] J. A. Weibel and S. V. Garimella, "Visualization of vapor formation regimes during capillary-fed boiling in sintered-powder heat pipe wicks," International Journal of Heat and Mass Transfer, vol. 55, pp. 3498-3510, 2012.

[22] S. Sudhakar, J. A. Weibel, and S. V. Garimella, "Design of an Area-Scalable Two-Layer Evaporator Wick for High-Heat-Flux Vapor Chambers," IEEE Transactions on Components, Packaging and Manufacturing Technology, early access, doi: 10.1109/TCPMT.2018.2860961.

[23] S. Sarangi, J. A. Weibel, and S. V. Garimella, "Effect of particle size on surface-coating enhancement of pool boiling heat transfer," International Journal of Heat and Mass Transfer, vol. 81, pp. 103-113, 2015.

[24] G. S. Hwang, E. Fleming, B. Carne, S. Sharratt, Y. Nam, P. Dussinger, Y. S. Ju and M. Kaviany, "Multi-artery heat-pipe spreader: Lateral liquid supply," International Journal of Heat and Mass Transfer, vol. 54, pp. 2334-2340, 2011.

[25] T. W. Davis and S. V. Garimella, "Thermal Resistance Measurement across a Wick Structure Using a Novel Thermosyphon Test Chamber," Experimental Heat Transfer, vol. 21, pp. 143-154, 2008.

[26] User Guide for ANSYS FLUENT 12.0, Fluent Inc., 2009.

[27] M. R. S. Shirazy, S. Blais, and L. G. Fréchette, "Mechanism of wettability transition in copper metal foams: From superhydrophilic to hydrophobic," Applied Surface Science, vol. 258, pp. 6416-6424, 2012. 
[28] S. C. Wong and Y. C. Lin, "Effect of copper surface wettability on the evaporation performance: Tests in a flat-plate heat pipe with visualization," International Journal of Heat and Mass Transfer, vol. 54, pp. 3921-3926, 2011.

[29] Y. Nam, S. Sharratt, C. Byon, S. J. Kim, and Y. S. Ju, "Fabrication and Characterization of the Capillary Performance of Superhydrophilic $\mathrm{Cu}$ Micropost Arrays," Journal of Microelectromechanical Systems, vol. 19, pp. 581-588, 2010.

[30] G. S. Hwang, Y. Nam, E. Fleming, P. Dussinger, Y. S. Ju, and M. Kaviany, "Multi-artery heat pipe spreader: Experiment," International Journal of Heat and Mass Transfer, vol. 53, pp. 2662-2669, 2010.

[31] X. Chen, J. A. Weibel, and S. V. Garimella, "Exploiting Microscale Roughness on Hierarchical Superhydrophobic Copper Surfaces for Enhanced Dropwise Condensation," Advanced Materials Interfaces, vol. 2, p. 1400480, 2015.

[32] K. Brown, H. Coleman, and W. Steele, "Estimating uncertainty intervals for linear regression," Proceedings of the 33rd Aerospace Sciences Meeting and Exhibit, Reno, NV, p. 796, 1995.

[33] Y. Nam, S. Sharratt, G. Cha, and Y. S. Ju, "Characterization and Modeling of the Heat Transfer Performance of Nanostructured Cu Micropost Wicks," Journal of Heat Transfer, vol. 133, p. 101502, 2011.

[34] Q. Cai and Y. C. Chen, "Investigations of Biporous Wick Structure Dryout," Journal of Heat Transfer, vol. 134, p. 021503, 2011. 


\section{List of Figures}

Figure 1. Schematic diagram of the two-layer evaporator wick structure with sample liquid (in blue) and vapor (in red) flow pathways indicated. The darker shade of copper at the bottom represents the solid substrate and the lighter shade above is the porous wick. The evaporator wick region consists of a thin base wick layer which is fed by an array of vertical liquid-feeding posts from a thick cap wick layer above. Vents in the cap layer provide the vapor a pathway out of the wick. The view is cut by planes intersecting the liquid-feeding posts (left) and vapor vents (right) to illustrate the internal features and important dimensions.

Figure 2. Schematic diagrams showing the sequence of process steps in the fabrication of the two-layer wick: (a) copper substrate; (b) first sintering of porous copper layer; (c) laser machining to form liquidfeeding posts; (d) second sintering to add the cap layer; and (e) laser machining to form vapor vents. (f) An SEM image of the sintered copper particle morphology after step (b). (g) A top-down image of the fabricated two-layer wick.

Figure 3. (a) Schematic diagram of the capillary-fed boiling test facility that consists of a heater assembly inserted into the bottom wall of a saturated test chamber, with important components labeled. (b) Zoomed-in view near the wick fixture showing the liquid flow pathway from the periphery to the evaporator region; the dam prevents flooding over the top of the wick. (c) Exploded three-dimensional drawing of the heater assembly.

Figure 4 (a) An isometric view of the soldering assembly used to form a thermal connection between the wick substrate and the heater block. The substrate of the wick is held on a graphite base while the heated block is centered on it using a graphite stand. (b) A close-up view of the thermocouple locations $\left(T_{1}-T_{5}\right)$ and important dimensions of the heater block neck (not-to-scale).

Figure 5. Plan view and sectioned side view schematic diagrams (dimensions in $\mathrm{mm}$ ) of the (a) singlelayer evaporator wick and the (b) $5 \times 5$ and (c) $10 \times 10$ two-layer wick designs. For the two-layer wicks, the plan view is enlarged near the evaporator region to show the features: solid circles represent the vents in the cap layer, while the dashed circles represent the posts below the cap layer. The plan view diagrams are drawn to scale; the side view sections are not drawn to scale.

Figure 6. Steady-state (a) capillary-fed boiling curves and (b) wick thermal resistance as a function of input heat flux for the baseline single-layer wick and two-layer wicks. The last point in each curve represents the final steady-state data before the occurrence of complete dryout event. The error bars represent the measurement uncertainties.

Figure 7. Series of images (refer to Appendix B for videos) captured by the high-speed visualization setup, at (a) $45 \mathrm{~W} / \mathrm{cm}^{2}$, (b) $65 \mathrm{~W} / \mathrm{cm}^{2}$ and (c) $98 \mathrm{~W} / \mathrm{cm}^{2}$, showing the $1 \mathrm{~cm}^{2}$ heated area of the single-layer 
wick as viewed from the top. Section-view schematic diagrams are shown at each steady heat flux to illustrate the different boiling regimes in the wick.

Figure 8. Visualization images (refer to Appendix B for videos) showing the $1 \mathrm{~cm}^{2}$ heated area of the two-layer wick as viewed from the top, at (a) $98 \mathrm{~W} / \mathrm{cm}^{2}$, (b) $152 \mathrm{~W} / \mathrm{cm}^{2}$ and (c) $198 \mathrm{~W} / \mathrm{cm}^{2}$. Section-view schematic diagrams are shown to illustrate the different regimes of boiling in the wick. 


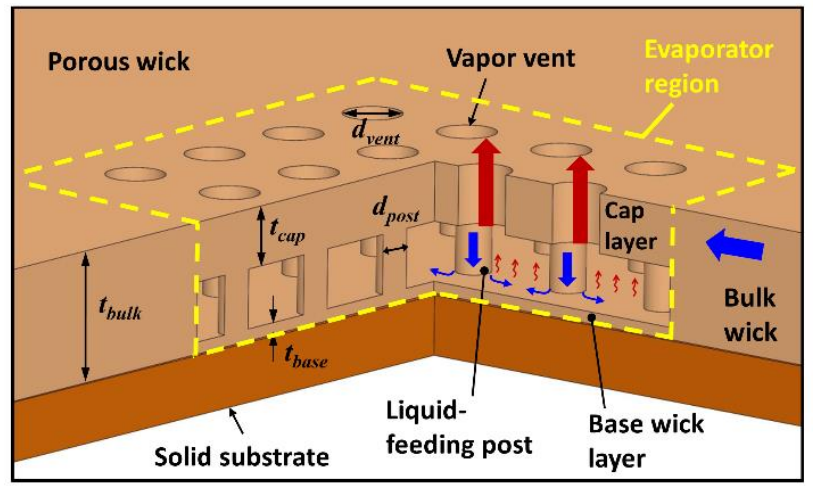

Figure 1. Schematic diagram of the two-layer evaporator wick structure with sample liquid (in blue) and vapor (in red) flow pathways indicated. The darker shade of copper at the bottom represents the solid substrate and the lighter shade above is the porous wick. The evaporator wick region consists of a thin base wick layer which is fed by an array of vertical liquid-feeding posts from a thick cap wick layer above. Vents in the cap layer provide the vapor a pathway out of the wick. The view is cut by planes intersecting the liquid-feeding posts (left) and vapor vents (right) to illustrate the internal features and important dimensions.

(note for editor: 1 column wide) 
(a)

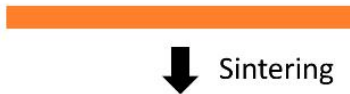

(b)

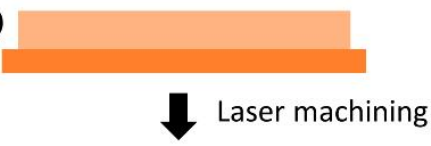

(c)

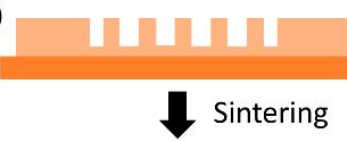

(d)

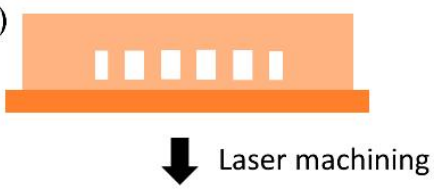

(e)

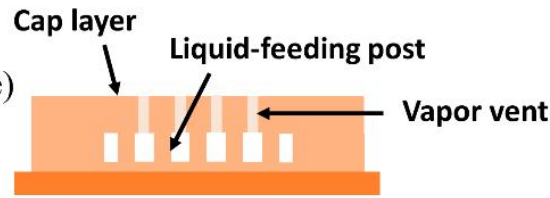

(f)

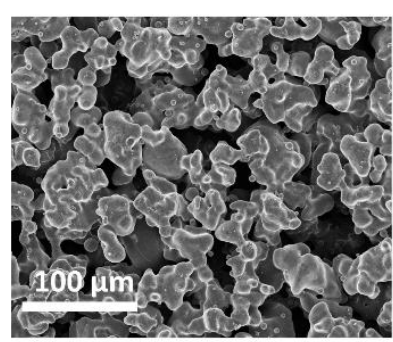

(g)

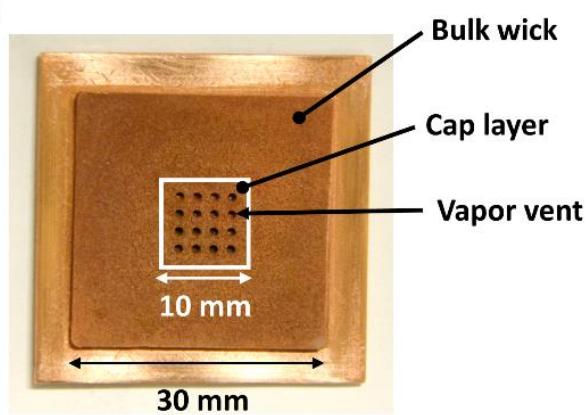

Figure 2. Schematic diagrams showing the sequence of process steps in the fabrication of the two-layer wick: (a) copper substrate; (b) first sintering of porous copper layer; (c) laser machining to form liquidfeeding posts; (d) second sintering to add the cap layer; and (e) laser machining to form vapor vents. (f) An SEM image of the sintered copper particle morphology after step (b). (g) A top-down image of the fabricated two-layer wick.

(note for editor: 1.5 columns wide) 

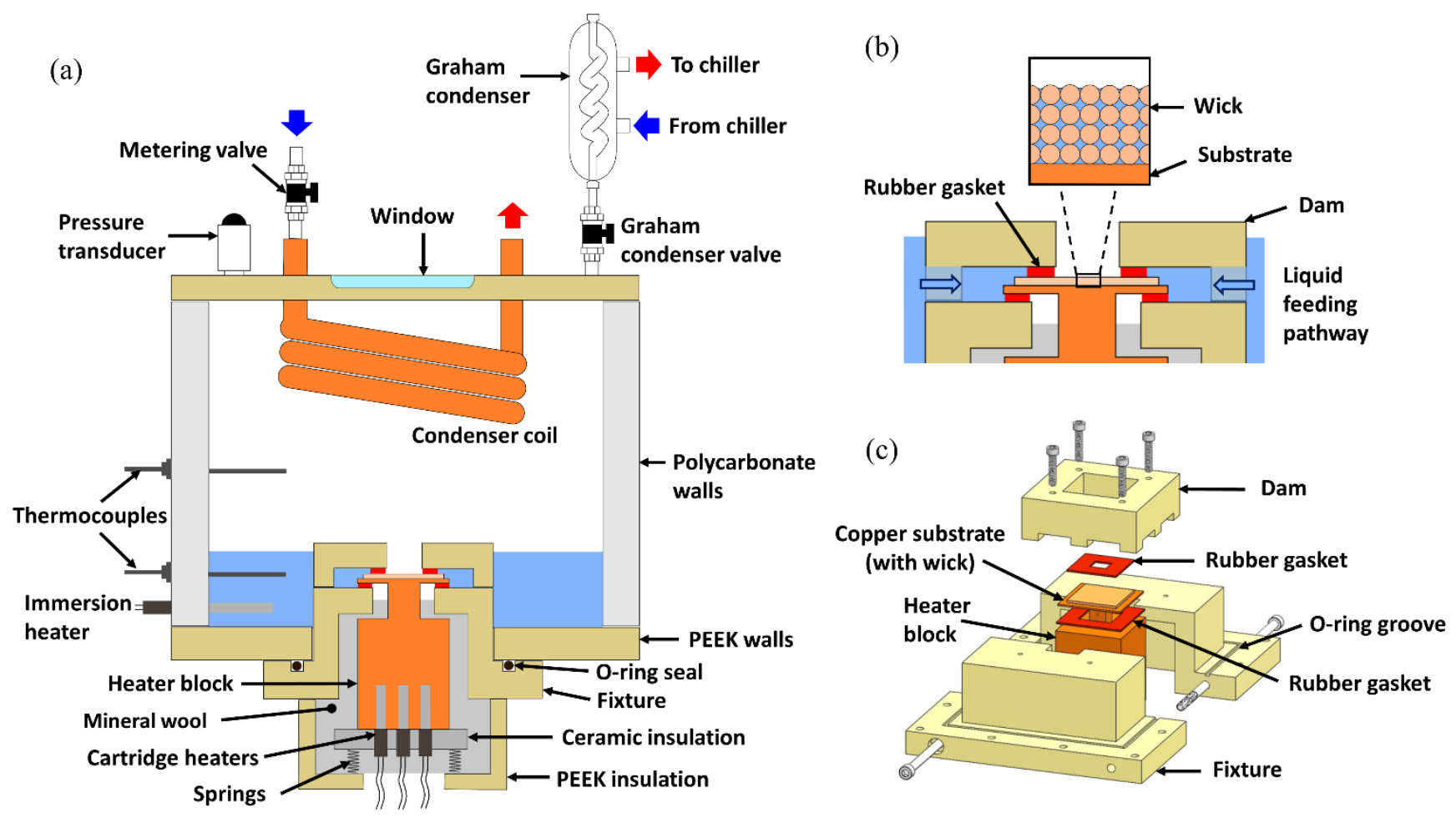

Figure 3. (a) Schematic diagram of the capillary-fed boiling test facility that consists of a heater assembly inserted into the bottom wall of a saturated test chamber, with important components labeled. (b) Zoomed-in view near the wick fixture showing the liquid flow pathway from the periphery to the evaporator region; the dam prevents flooding over the top of the wick. (c) Exploded three-dimensional drawing of the heater assembly.

(note for editor: 2 columns wide) 

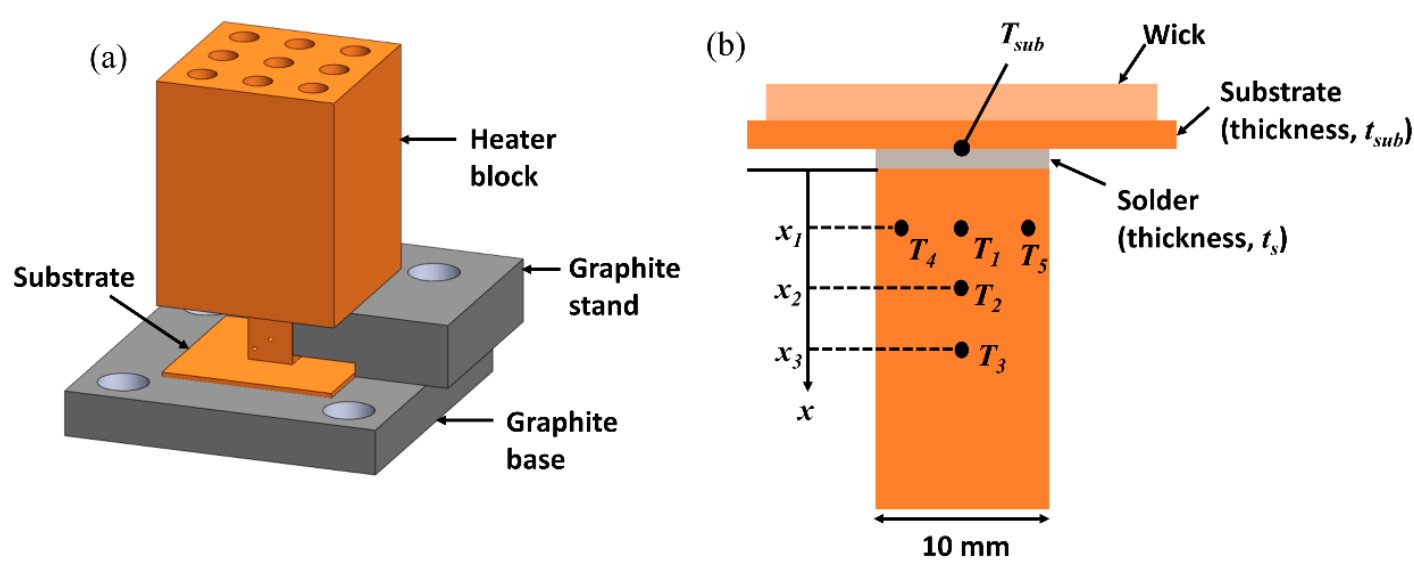

Figure 4 (a) An isometric view of the soldering assembly used to form a thermal connection between the wick substrate and the heater block. The substrate of the wick is held on a graphite base while the heated block is centered on it using a graphite stand. (b) A close-up view of the thermocouple locations $\left(T_{1}-T_{5}\right)$ and important dimensions of the heater block neck (not-to-scale).

(note for editor: 1.5 columns wide) 


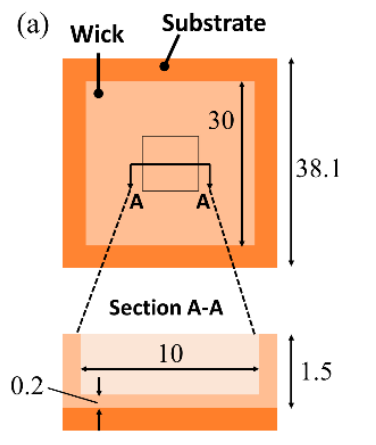

(b)

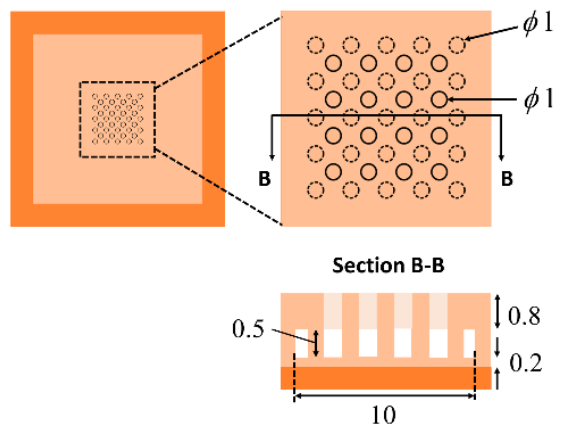

(c)

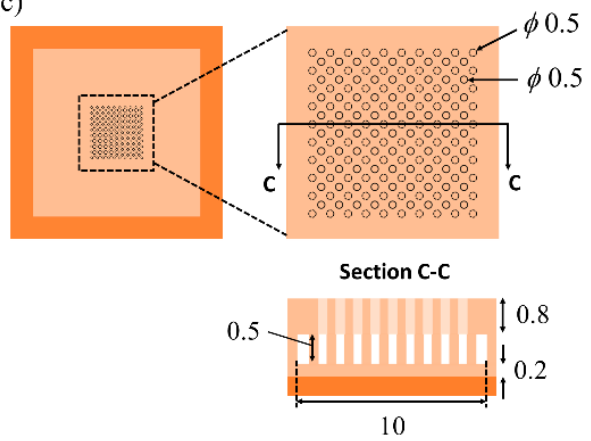

Figure 5. Plan view and sectioned side view schematic diagrams (dimensions in $\mathrm{mm}$ ) of the (a) single-layer evaporator wick and the (b) $5 \times 5$ and (c) $10 \times 10$ two-layer wick designs. For the two-layer wicks, the plan view is enlarged near the evaporator region to show the features: solid circles represent the vents in the cap layer, while the dashed circles represent the posts below the cap layer. The plan view diagrams are drawn to scale; the side view sections are not drawn to scale.

(note for editor: 2 columns wide) 


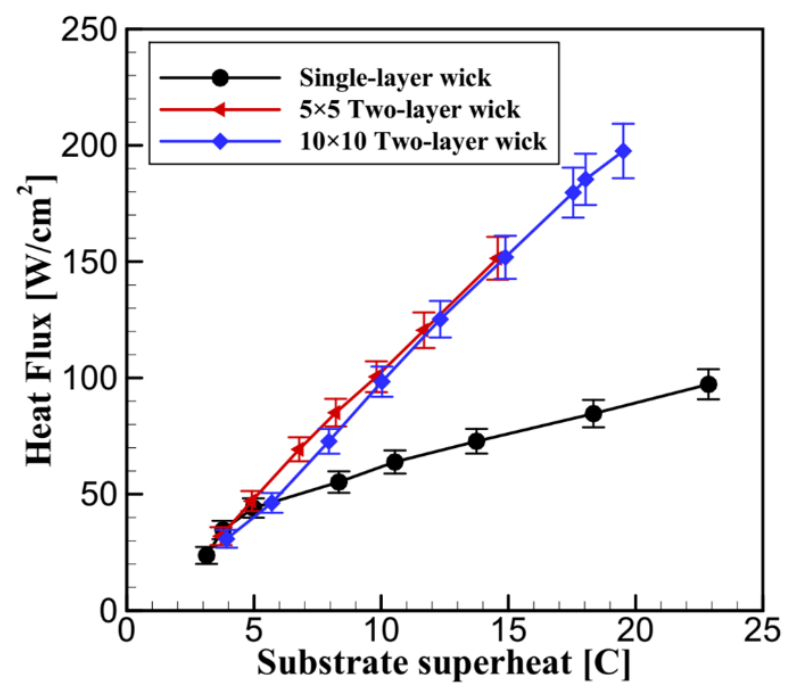

(a)

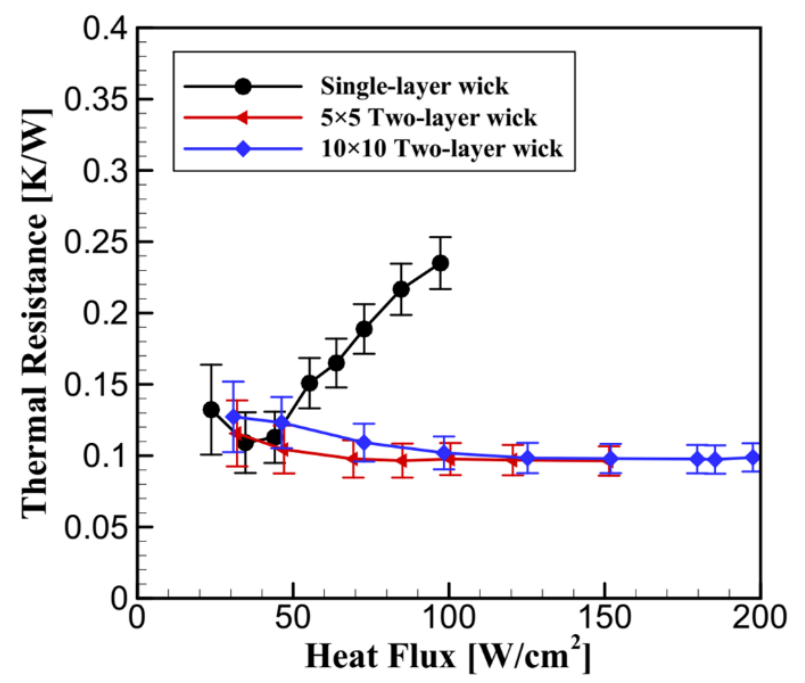

(b)

Figure 6. Steady-state (a) capillary-fed boiling curves and (b) wick thermal resistance as a function of input heat flux for the baseline single-layer wick and two-layer wicks. The last point in each curve represents the final steady-state data before the occurrence of complete dryout event. The error bars represent the measurement uncertainties.

(note for editor: 1 column wide) 
(a) $45 \mathrm{~W} / \mathrm{cm}^{2}$
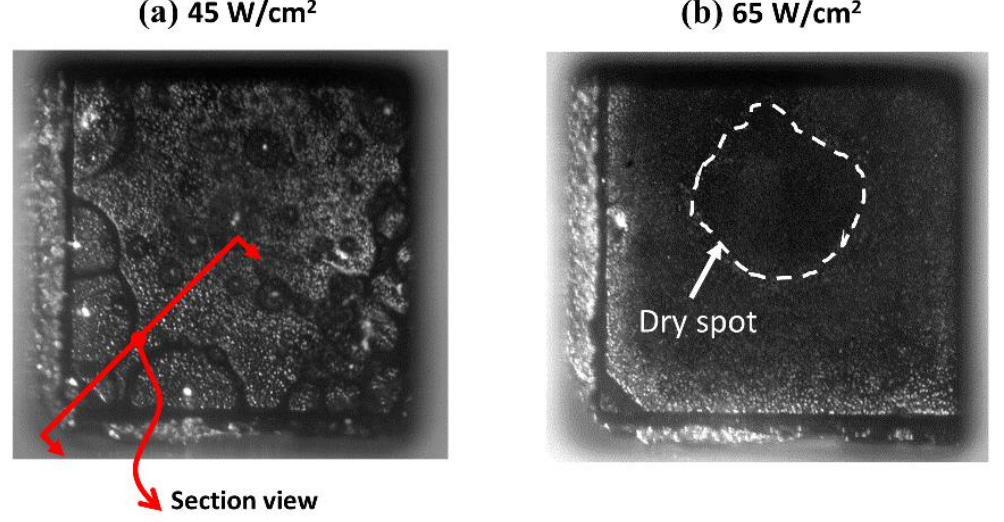

(b) $65 \mathrm{~W} / \mathrm{cm}^{2}$

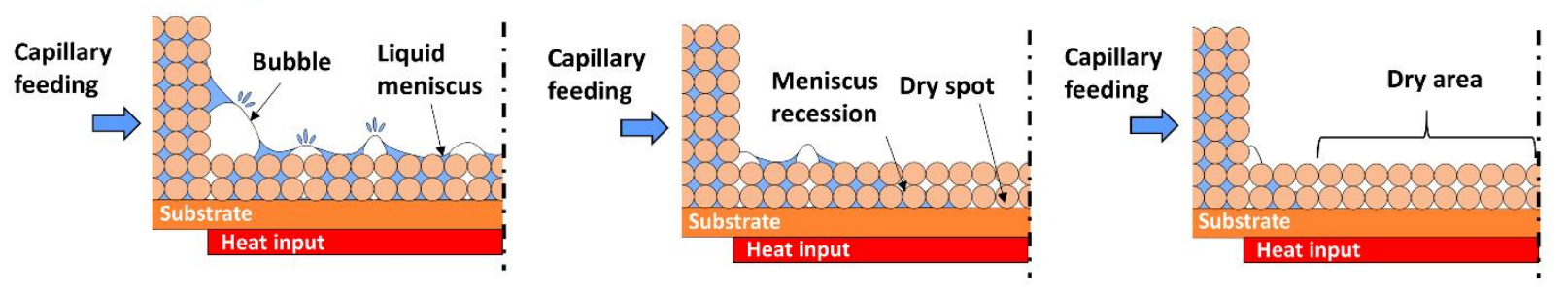

(c) $98 \mathrm{~W} / \mathrm{cm}^{2}$

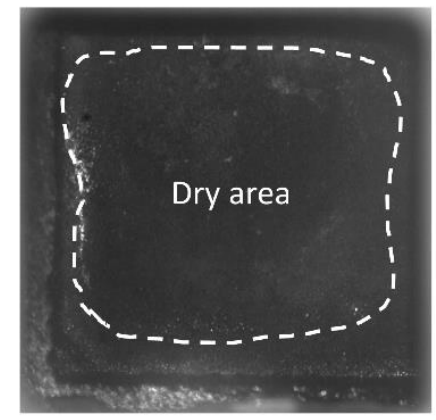

\section{.}

Figure 7. Series of images (refer to Appendix B for videos) captured by the high-speed visualization setup, at (a) $45 \mathrm{~W} / \mathrm{cm}^{2}$, (b) $65 \mathrm{~W} / \mathrm{cm}^{2}$ and (c) $98 \mathrm{~W} / \mathrm{cm}^{2}$, showing the $1 \mathrm{~cm}^{2}$ heated area of the single-layer wick as viewed from the top. Section-view schematic diagrams are shown at each steady heat flux to illustrate the different boiling regimes in the wick.

(note for editor: 2 columns wide) 
(a) $98 \mathrm{~W} / \mathrm{cm}^{2}$

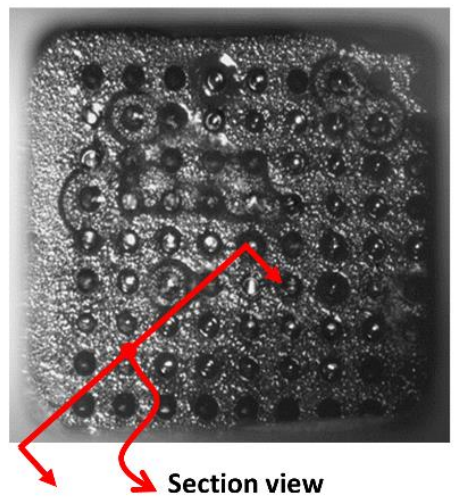

Bubble

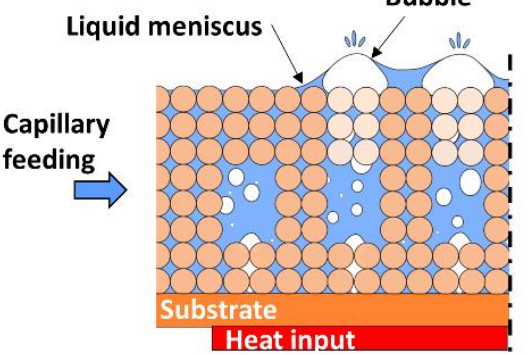

(b) $152 \mathrm{~W} / \mathrm{cm}^{2}$
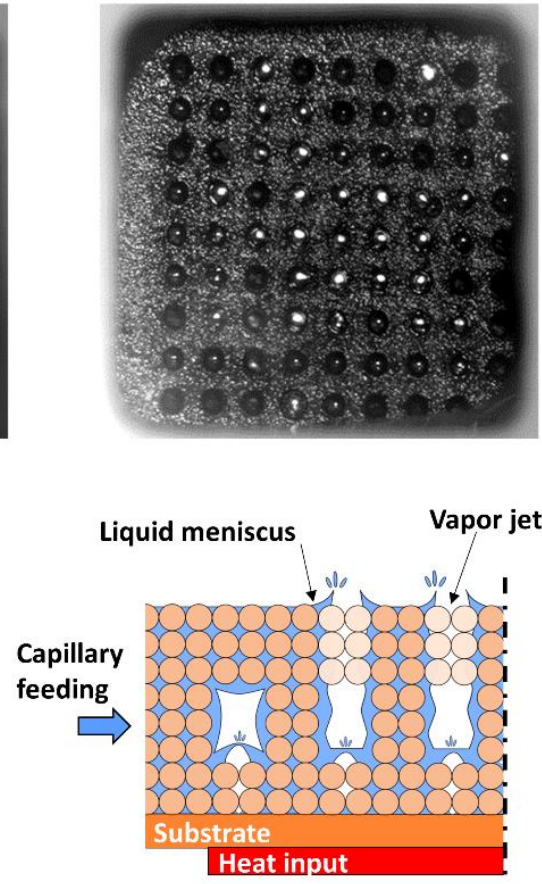

(c) $198 \mathrm{~W} / \mathrm{cm}^{2}$

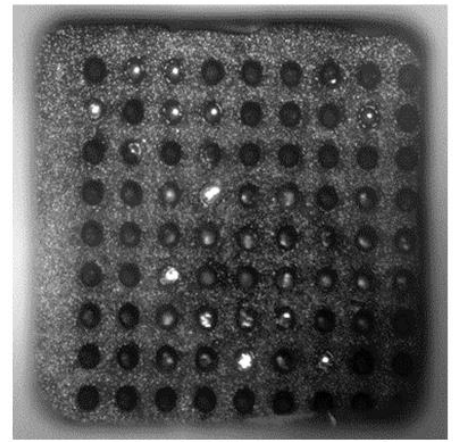

Meniscus

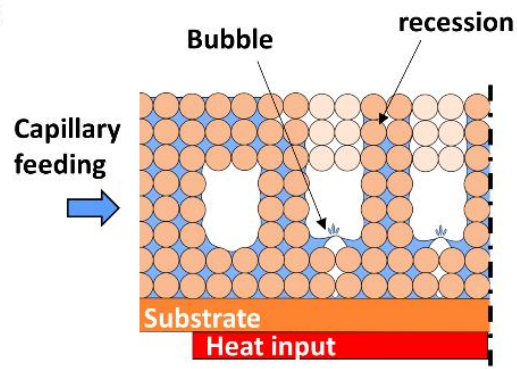

Figure 8. Visualization images (refer to Appendix B for videos) showing the $1 \mathrm{~cm}^{2}$ heated area of the twolayer wick as viewed from the top, at (a) $98 \mathrm{~W} / \mathrm{cm}^{2}$, (b) $152 \mathrm{~W} / \mathrm{cm}^{2}$ and (c) $198 \mathrm{~W} / \mathrm{cm}^{2}$. Section-view schematic diagrams are shown to illustrate the different regimes of boiling in the wick.

(note for editor: 2 columns wide) 